\title{
Adaptabilidade e estabilidade de cultivares de milho no Nordeste brasileiro
}

\author{
Hélio Wilson Lemos de Carvalho(1), Mílton José Cardoso(2), Maria de Lourdes da Silva Leal(1), \\ Manoel Xavier dos Santos ${ }^{(3)}$, José Nildo Tabosa ${ }^{(4)}$ e Evanildes Menezes de Souza ${ }^{(5)}$
}

\begin{abstract}
(1)Embrapa Tabuleiros Costeiros, Caixa Postal 44, CEP 49025-040 Aracaju, SE. E-mail: helio@cpatc.embrapa.br, lurdinha@cpatc.embrapa.br (2)Embrapa Meio-Norte, Caixa Postal 001, CEP 64006-220 Teresina, PI. E-mail: milton@cpamn.embrapa.br (3)Embrapa Milho e Sorgo, Caixa Postal 152, CEP 35701-970 Sete Lagoas, MG. E-mail: xavier@cnpms.embrapa.br (4)Empresa Pernambucana de Pesquisa Agropecuária, Caixa Postal 1022, CEP 50761-000 Recife, PE. E-mail: tabosa@ipa.br (5)Universidade Federal de Sergipe, Av. Marechal Rondon, s/no, Jardim Rosa Elze, CEP 49100-000 São Cristovão, SE. E-mail: eva@cpatc.embrapa.br
\end{abstract}

\begin{abstract}
Resumo - Foram avaliadas quarenta e seis cultivares de milho em dois anos, em 11 locais do Nordeste brasileiro, no biênio 2001-2002, em blocos ao acaso, com três repetições, com o objetivo de avaliar a adaptabilidade e a estabilidade desses materiais, para fins de recomendação na região. As cultivares mostraram comportamento diferenciado entre si, na média dos ambientes. A magnitude da variância da interação cultivares x locais foi mais expressiva que a magnitude da variância da interação cultivares $\mathrm{x}$ anos, o que sugere que as avaliações devam ser realizadas em um maior número de locais. As cultivares avaliadas diferiram quanto à adaptabilidade e à estabilidade; são de grande importância para o Nordeste brasileiro os híbridos e variedades de melhor adaptação ( $\mathrm{b}_{0}>$ média geral) e com estimativas de $\mathrm{b}_{1}$ semelhantes à unidade (adaptabilidade geral).
\end{abstract}

Termos para indexação: Zea mays, variedades, híbridos, interação genótipos x ambientes.

\section{Adaptability and stability of maize cultivars in Brazilian Northeast}

\begin{abstract}
Forty six maize cultivars were evaluated during two years in 11 different places of Brazilian Northeast Region. Trials were carried out during the biennium 2001/2002 using experimental randomized block design, three repetitions, in order to know the adaptability and stability for cultivars recommendation. It was verified that the cultivars showed differentiated behavior among themselves in the mean of environments. The magnitude of the variance for local $\mathrm{x}$ cultivars interaction was more expressive than cultivars $\mathrm{x}$ years interaction, which suggests that the evaluations have to be done in a larger number of environments. Evaluated cultivars differed in adaptability and stability, and are very important for Brazilian Northeast Region.
\end{abstract}

Index terms: Zea mays, varieties, hybrids, genotype x environment interaction.

\section{Introdução}

Nos últimos anos, a produtividade do milho no Nordeste brasileiro vem aumentando, em conseqüência da importância econômica desse cereal, e do uso de variedades e híbridos, que atendem aos diferentes sistemas de produção ali predominantes.

Nessa ampla região ocorrem condições ambientais distintas (Silva et al., 1993), e o milho, com algumas restrições, é cultivado em todas elas. Considerando-se esse aspecto, e aquele relacionado aos diferentes sistemas de produção, prevalecentes na região, infere-se que é de interesse o desenvolvimento de um programa de avaliação de variedades e híbridos de milho, com o objetivo de subsidiar os agricultores na escolha de materi- ais de melhor adaptação, e que sejam portadores de atributos agronômicos desejáveis.

Os híbridos têm se destacado em áreas do Nordeste brasileiro que utilizam tecnologias modernas de produção, como, por exemplo, os cerrados do Oeste baiano, do Sul do Maranhão e do sudoeste do Piauí (Cardoso et al., 2000; Carvalho et al., 2001, 2002); os híbridos predominam, portanto, em sistemas de produção onde o uso de insumos modernos é uma constante. As variedades melhoradas, por serem genótipos de menor adaptação quando comparadas aos híbridos, em diversos trabalhos de competição de cultivares realizados no Nordeste brasileiro, predominam em sistemas de produção dos pequenos e médios produtores rurais, pois lhes faltam recursos para investir em tecnologias de pro- 
dução (Cardoso et al., 2000; Carvalho et al., 2001, 2002). Apesar disso, algumas variedades têm apresentado produtividade média de grãos semelhantes à de alguns híbridos, segundo esses autores, o que justifica seu emprego em sistemas de produção mais sofisticados.

Anualmente, nessa região, variedades e híbridos são postos a competir em vários ambientes. Nesse caso, a classificação relativa entre eles pode não ser coincidente, o que dificulta a identificação de materiais efetivamente superiores. Esse efeito é minimizado, mediante a seleção de genótipos com maior estabilidade fenotípica (Ramalho et al., 1993).

Diversos trabalhos ressaltam a importância e a influência da interação cultivares $\mathrm{x}$ ambientes, principalmente nas fases do programa que envolvem a avaliação final e a recomendação de cultivares (Arias, 1996; Carneiro, 1998; Gama et al., 2000; Ribeiro et al., 2000; Carbonell et al., 2001; Carvalho et al., 2002).

O objetivo deste trabalho foi avaliar a adaptabilidade e a estabilidade de variedades e híbridos de milho, visando à recomendação desses materiais, para as condições ambientais do Nordeste brasileiro.

\section{Material e Métodos}

No biênio 2001-2002 foram realizados 22 ensaios de milho no Nordeste brasileiro, sendo 11 concluídos no ano agrícola de 2001 e, os outros 11, em 2002. Dentro de cada ano agrícola, esses ensaios foram distribuídos nos Estados do Maranhão (três ensaios), Piauí (três ensaios), Pernambuco (dois ensaios), Sergipe (dois ensaios) e Bahia (dois ensaios). Os ambientes mostraram diferentes regimes pluviométricos, observando-se uma variação de 348 mm, em Caruaru, PE, no ano agrícola de 2001, a 1.057 mm, em São Raimundo das Mangabeiras, MA, no ano agrícola de 2002 (Tabela 1). Os municípios estão compreendidos entre os paralelos $2^{\circ} 63^{\prime}$, em Parnaíba, PI, e 14³6', em Barra do Choça, BA, e as altitudes variaram de $15 \mathrm{~m}$, em Parnaíba, a $880 \mathrm{~m}$, em Barra do Choça (Tabela 2). O plantio foi feito no início das chuvas, dentro de cada área experimental (Tabela 1).

Foram avaliadas 46 cultivares (25 híbridos e 21 variedades), em blocos ao acaso, com três repetições. Cada parcela constou de quatro fileiras de $5 \mathrm{~m}$ de comprimento, em espaços de $0,80 \mathrm{~m}$, e $0,40 \mathrm{~m}$ entre covas dentro das fileiras. Foram colocadas três sementes por cova, deixando-se, após o desbaste, duas plantas por

Tabela 1. Índices pluviais (mm) durante o período experimental. Região Nordeste do Brasil, biênio 2000/2001-2001/2002.

\begin{tabular}{|c|c|c|c|c|c|c|c|c|c|c|c|}
\hline Municípios & Dez. & Jan. & Fev. & Mar. & Abr. & Maio & Jun. & Jul. & Ago. & Set. & Total \\
\hline & \multicolumn{11}{|c|}{$2000 / 2001$} \\
\hline S. R. das Mangabeiras & $369^{(1)}$ & 136 & 80 & 177 & - & - & - & - & - & - & 762 \\
\hline Brejo & - & $254^{(1)}$ & 240 & 244 & 312 & - & - & - & - & - & 1.050 \\
\hline Barra do Corda & - & $108^{(1)}$ & 49 & 203 & 97 & - & - & - & - & - & 457 \\
\hline B. Grande do Ribeiro & $389^{(1)}$ & 154 & 278 & 222 & - & - & - & - & - & - & 1.043 \\
\hline Teresina & - & $254^{(1)}$ & 240 & 244 & 312 & - & - & - & - & - & 1.050 \\
\hline Parnaíba & - & $175^{(1)}$ & 245 & 119 & 379 & - & - & - & - & - & 918 \\
\hline Araripina & - & $53^{(1)}$ & 157 & 88 & 58 & - & - & - & - & - & 356 \\
\hline Nossa Sra. das Dores & - & - & - & - & - & $173^{(1)}$ & 173 & 171 & 35 & - & 552 \\
\hline Simão Dias & - & - & - & - & - & $158^{(1)}$ & 109 & 127 & 92 & - & 482 \\
\hline \multirow[t]{2}{*}{ Barra do Choça } & - & $128^{(1)}$ & 61 & 37 & 53 & - & - & - & - & - & 279 \\
\hline & \multicolumn{11}{|c|}{$2001 / 2002$} \\
\hline S. R. das Mangabeiras & $189^{(1)}$ & 523 & 71 & 274 & - & - & - & - & - & - & 1.057 \\
\hline Brejo & - & $68^{(1)}$ & 46 & 152 & 408 & - & - & - & - & - & 674 \\
\hline B. Grande do Ribeiro & $230^{(1)}$ & 512 & 84 & 166 & - & - & - & - & - & - & 992 \\
\hline Teresina & - & $360^{(1)}$ & 94 & 226 & 134 & - & - & - & - & - & 817 \\
\hline Parnaíba & - & $221^{(1)}$ & 109 & 189 & 250 & - & - & - & - & - & 769 \\
\hline Caruaru & - & - & - & - & - & $125^{(1)}$ & 115 & 69 & 63 & - & 372 \\
\hline Araripina & - & $157^{(1)}$ & 81 & 140 & 38 & - & - & - & - & - & 416 \\
\hline Nossa Sra. das Dores & - & - & - & - & - & $229^{(1)}$ & 150 & 30 & - & - & 406 \\
\hline Simão Dias & - & - & - & - & - & $159^{(1)}$ & 201 & - & 84 & - & 444 \\
\hline Barra do Choça & - & $288^{(1)}$ & 140 & 82 & 69 & - & - & - & - & - & 579 \\
\hline
\end{tabular}

(1)Mês de plantio. 
cova. Foram colhidas as duas fileiras centrais de forma integral, correspondentes a uma área útil de $8 \mathrm{~m}^{2}$. As adubações foram realizadas conforme a análise de solo de cada área experimental.

Os pesos de grãos (15\%) foram submetidos à análise de variância, pelo modelo de blocos ao acaso. A análise de variância conjunta obedeceu ao critério de homogeneidade dos quadrados médios residuais (Pimentel-Gomes, 1985), e foram realizadas conforme Vencovsky \& Barriga (1992), considerando-se como aleatórios os efeitos de blocos, anos e locais, e como fixo o efeito de cultivares. As referidas análises foram efetuadas, utilizando-se o Statistical Analysis System (SAS Institute, 1996), para dados balanceados (PROCANOVA).

Os parâmetros de adaptabilidade e estabilidade foram estimados pelo método de Cruz et al. (1989), que se baseia na análise de regressão bissegmentada, tendo como parâmetros de adaptabilidade a média $\left(b_{0}\right)$, a resposta linear aos ambientes desfavoráveis $\left(b_{1}\right)$ e aos ambientes favoráveis $\left(b_{1}+b_{2}\right)$. Foi utilizado o seguinte modelo: $\mathrm{Y}_{\mathrm{ij}}=\mathrm{b}_{\mathrm{oi}}+\mathrm{b}_{1 \mathrm{i}} \mathrm{I}_{\mathrm{J}}+\mathrm{b}_{2 \mathrm{i}} \mathrm{T}\left(\mathrm{I}_{\mathrm{j}}\right)+\sigma_{\mathrm{ij}}+\mathrm{e}_{\mathrm{ij}}$, onde $\mathrm{Y}_{\mathrm{ij}}$ é média da cultivar i no ambiente $\mathrm{j}$; $\mathrm{I}_{\mathrm{j}}$ é o óndice ambiental; $\mathrm{T}\left(\mathrm{I}_{\mathrm{j}}\right)=0$ se $\mathrm{I}_{\mathrm{J}}<0 ; \mathrm{T}\left(\mathrm{I}_{\mathrm{J}}\right)=\mathrm{I}_{\mathrm{j}}-\mathrm{I}_{+}$se $\mathrm{I}_{\mathrm{j}}>0$, sendo $\mathrm{I}_{+}$a média dos índices $\mathrm{I}_{\mathrm{j}}$ positivos; $\mathrm{b}_{0 \mathrm{i}}$ é a média geral da cultivar i; $\mathrm{b}_{1 \mathrm{i}}$ é o coeficiente de regressão linear associado à variável $\mathrm{I}_{\mathrm{j}}$; $\mathrm{b}_{2 \mathrm{i}}$ é o coeficiente de regressão linear associado à variável $\mathrm{T}\left(\mathrm{I}_{\mathrm{j}}\right)$; $\sigma_{\mathrm{ji}}$ é o desvio da regressão linear; $\mathrm{e}_{\mathrm{ij}}$ é o erro médio experimental.

\section{Resultados e Discussões}

Foram observadas diferenças entre as cultivares, o que evidencia comportamento diferenciado entre os

Tabela 2. Coordenadas geográficas dos locais e tipos de solo das áreas experimentais.

\begin{tabular}{|c|c|c|c|c|}
\hline Municípios & $\begin{array}{c}\text { Latitude } \\
\text { (S) }\end{array}$ & $\begin{array}{l}\text { Longitude } \\
\text { (W) }\end{array}$ & $\begin{array}{c}\text { Altitude } \\
(\mathrm{m})\end{array}$ & Tipo de solo \\
\hline & \multicolumn{4}{|c|}{ Maranhão } \\
\hline S.R. das Mangabeiras & $7^{\circ} 22^{\prime}$ & $45^{\circ} 36^{\prime}$ & 225 & Alissolo Verm \\
\hline Brejo & & $42^{\circ}$ & 55 & Latossolo Vern \\
\hline \multirow[t]{2}{*}{ Barra do Corda } & 5 & 4 & 84 & Alissolo Vermelho-Amarelo \\
\hline & \multicolumn{4}{|c|}{ Piaui } \\
\hline B. Grande do Ribeiro & $7^{\circ} 32^{\prime}$ & $45^{\circ} 14^{\prime}$ & 325 & Neossolo Quartzarênico \\
\hline Tere & $5^{\circ} 5^{\prime}$ & $42^{\circ} 49^{\prime}$ & 72 & Neossolo Flúvico \\
\hline \multirow[t]{2}{*}{ Parnaíba } & $2^{\circ} 63^{\prime}$ & $41^{\circ} 41^{\prime}$ & 15 & Neossolo Quartzarênico \\
\hline & \multicolumn{4}{|c|}{ Pernambuco } \\
\hline Caruaru & $8^{\circ} 34^{\prime}$ & $38^{\circ} 0^{\prime}$ & 537 & Alissolo Vermelho-Amarelo \\
\hline \multirow[t]{2}{*}{ Araripina } & $7^{\circ} 33^{\prime}$ & $40^{\circ} 34^{\prime}$ & 620 & Latossolo Vermelho-Amarelo \\
\hline & \multicolumn{4}{|c|}{ Sergipe } \\
\hline & $10^{\circ} 30^{\prime}$ & $37^{\circ} 13^{\prime}$ & 200 & Latossolo Vermelho-Amar \\
\hline \multirow{2}{*}{ Simão Dias } & $10^{\circ} 44^{\prime}$ & $37^{\circ} 48^{\prime}$ & 283 & Neossolo Flúvico \\
\hline & \\
\hline
\end{tabular}

materiais, dentro de cada área experimental (Tabela 3). Os coeficientes de variação obtidos oscilaram de 7\% a $19 \%$, o que demonstra boa precisão dos ensaios, conforme Scapim et al. (1995). A produtividade média de grãos variou de $3.430 \mathrm{~kg} \mathrm{ha}^{-1}$, no ensaio de Araripina, PE, no ano agrícola de 2001, a $8.445 \mathrm{~kg} \mathrm{ha}^{-1}$, em Simão Dias, SE, nesse mesmo ano agrícola. Essa oscilação deveu-se à variações pronunciadas nas condições climáticas, especialmente na quantidade e na distribuição de chuvas (Tabela 1), e nas condições de solo dos locais em que foram realizados os ensaios (Tabela 2), o que se reflete, conseqüentemente, também no comportamento diferenciado das cultivares nesses diferentes locais (Tabela 4).

No ano agrícola de 2000-2001, os municípios de São Raimundo das Mangabeiras e Barra do Corda, MA, Baixa Grande do Ribeiro, Parnaíba e Teresina, PI, Nossa Senhora das Dores e Simão Dias, SE, e Barra do Choça, BA, mostraram produtividade média de grãos superior à média geral $\left(5.685 \mathrm{~kg} \mathrm{ha}^{-1}\right)$. No ano agrícola de 2002, a produtividade média obtida nos municípios de São Raimundo das Mangabeiras e Brejo, MA, Teresina e Parnaíba, PI, e Nossa Senhora das Dores, SE, superou também a média geral. Esses ambientes expressaram melhor potencialidade no desenvolvimento da cultura do milho, sobressaindo-se como ambientes mais propícios aqueles com produtividade média acima de $6.500 \mathrm{~kg} \mathrm{ha}^{-1}$.

Tabela 3. Resumo das análises de variância da produtividade de grãos $\left(\mathrm{kg} \mathrm{ha}^{-1}\right)$ de cada ensaio. Região Nordeste do Brasil, biênio 2000/2001-2001/2002.

\begin{tabular}{|c|c|c|c|c|}
\hline \multirow[t]{2}{*}{ Município } & \multicolumn{2}{|c|}{ Quadrado médio } & \multirow{2}{*}{ Média } & \multirow{2}{*}{$\mathrm{CV}(\%)$} \\
\hline & Cultivares & Resíduo & & \\
\hline & \multicolumn{4}{|c|}{$2000 / 2001$} \\
\hline São Raimundo das Mangabeiras & $2.122 .873 * *$ & 579.472 & 7.595 & 10 \\
\hline Brejo & $3.590 .164 * *$ & 305.081 & 4.534 & 12 \\
\hline Barra do Corda & $2.980 .273 * *$ & 332.646 & 5.948 & 10 \\
\hline Baixa Grande do Ribeiro & $2.762 .571^{* *}$ & 264.777 & 7.185 & 7 \\
\hline Teresina & $3.584 .461^{* *}$ & 593.429 & 7.114 & 11 \\
\hline Parnaíba & $2.067 .419^{* *}$ & 456.701 & 7.346 & 9 \\
\hline Caruaru & $715.179 * *$ & 182.080 & 3.639 & 12 \\
\hline Araripina & $1.092 .700 * *$ & 262.034 & 3.430 & 15 \\
\hline Nossa Sra. das Dores & $2.694 .609 * *$ & 538.835 & 6.216 & 12 \\
\hline Simão Dias & $4.421 .788^{* *}$ & 367.470 & 8.445 & 7 \\
\hline \multirow[t]{2}{*}{ Barra do Choça } & $5.537 .111 * *$ & 744.321 & 5.715 & 15 \\
\hline & \multicolumn{4}{|c|}{$2001 / 2002$} \\
\hline São Raimundo das Mangabeiras & $2.010 .375^{* *}$ & 262.974 & 6.154 & 8 \\
\hline Brejo & $1.738 .012 * *$ & 434.053 & 6.680 & 10 \\
\hline Barra do Corda & $1.429 .501^{* *}$ & 427.844 & 4.851 & 13 \\
\hline Baixa Grande do Ribeiro & $710.527 * *$ & 185.335 & 3.800 & 11 \\
\hline Teresina & $1.933 .041^{* *}$ & 314.760 & 6.694 & 8 \\
\hline Parnaíba & $1.754 .350^{* *}$ & 254.583 & 6.775 & 7 \\
\hline Caruaru & $3.769 .754 * *$ & 199.356 & 3.687 & 12 \\
\hline Araripina & $2.205 .049 * *$ & 409.055 & 3.555 & 18 \\
\hline Nossa Sra. das Dores & $6.983 .593 * *$ & 491.632 & 6.529 & 11 \\
\hline Simão Dias & $2.024 .599 * *$ & 381.458 & 5.190 & 12 \\
\hline Barra do Choça & $2.441 .076^{* *}$ & 555.271 & 3.994 & 19 \\
\hline
\end{tabular}

**Significativo a $1 \%$ de probabilidade pelo teste $\mathrm{F}$. 
Houve diferenças em relação a anos e locais (Tabela 4). Detectou-se, também, diferenças no desempenho das cultivares avaliadas, na média dos ambientes.

As diferenças significativas das interações cultivares $\mathrm{x}$ locais e cultivares $\mathrm{x}$ anos revelaram que as classificações das cultivares não foram coincidentes nos locais e anos de avaliação, respectivamente (Tabela 4).

Considerando-se as esperanças dos quadrados médios (Vencovsky \& Barriga, 1992), foram estimados os componentes da variância das interações. Constatouse que a magnitude da variância da interação cultivares $\mathrm{x}$ locais $\left(\sigma^{2}{ }_{\mathrm{cxl}}=88.781\right)$ foi mais expressiva do que a magnitude da variância da interação cultivares $\mathrm{x}$ anos $\left(\sigma_{\text {cха }}^{2}=47.739\right)$, o que evidencia que é mais vantajoso avaliar as cultivares em um maior número de locais do que em um maior número de anos, e esta informação é de grande importância para orientação de futuros trabalhos de avaliação de cultivares, conforme Atroch et al. (2000).

Constatada a presença da interação cultivares x locais, procurou-se verificar as respostas de cada uma delas nos ambientes considerados, pelo método de Cruz et al. (1989), que descreve como cultivar ideal aquela que expressa alta produtividade média $\left(\mathrm{b}_{0}>\right.$ média geral), adaptabilidade nos ambientes desfavoráveis ( $b_{1} 0$ menor possível), responsividade à variância ambiental $\left(b_{1}+b_{2}\right.$ o maior possível) e, finalmente, variância dos desvios da regressão igual a zero (alta estabilidade nos ambientes considerados). Além do preconizado pelo modelo proposto, considerou-se como cultivar de melhor adaptação, aquela com produtividade média de grãos acima da média geral (Vencovsky \& Barriga, 1992).

Quanto ao coeficiente de regressão $\left(b_{1}\right)$, que corresponde à resposta linear da cultivar à variação nos

Tabela 4. Análises de variância conjunta de rendimento de grãos ( $\left.\mathrm{kg} \mathrm{ha}^{-1}\right)$, de 46 cultivares de milho, em 11 locais e 2 anos de avaliação (22 ambientes), no Nordeste brasileiro, no biênio 2000/2001-2001/2002.

\begin{tabular}{lcc}
\hline Fontes de variação & Graus de liberdade & Quadrados médios \\
\hline Blocos (ano x local) & 44 & $1.050 .283 * *$ \\
Ano (A) & 1 & $537.591 .862 * *$ \\
Local (L) & 10 & $448.784 .093 * *$ \\
Interação AxL & 10 & $177.552 .596 * *$ \\
Cultivares (C) & 45 & $24.882 .175 * *$ \\
Interação AxC & 45 & $1.966 .293 * *$ \\
Interação LxC & 450 & $1.718 .748 * *$ \\
Interação AxLxC & 450 & $1.433 .610^{*} *$ \\
Erro & 1.980 & 387.326 \\
**Significativo a 1\% de probabilidade pelo teste F. Média $=5.685 \mathrm{~kg} \mathrm{ha}^{-1} ;$ \\
CV $=11 \%$.
\end{tabular}

ambientes desfavoráveis, as estimativas variaram de 0,55 a 1,22 , respectivamente, em relação à variedade CMS 47 e ao híbrido Pioneer 3041, sendo ambos estatisticamente diferentes da unidade (Tabela 5). Considerando-se as 25 cultivares que expressaram melhor adaptação ( $\mathrm{b}_{0}>$ média geral), 12 apresentaram estimativas de $\mathrm{b}_{1}$ significativamente diferentes da unidade, e 13 apresentaram estimativas de $b_{1}$ não significativas $\left(b_{1}=1\right)$, o que evidencia comportamento diferenciado dessas cultivares em ambientes desfavoráveis. Os híbridos Pioneer 3021, Agromen 3050, SHS 5050, Pioneer 30 F 88, Colorado 32, A 2560, BR 3123 e BRS 3101, e a variedade AL Bandeirante mostraram ser muito exigentes nas condições desfavoráveis $\left(b_{1}>1\right)$. Os híbridos SHS 4040, Agromen 3100 e A 2288, por outro lado, mostraram ser pouco exigentes nessas mesmas condições. Com relação à resposta nos ambientes favoráveis, apenas os híbridos DAS 766, DAS 8550, Agromen 3150 e A 2288 responderam à melhoria ambiental $\left(\mathrm{b}_{1}+\mathrm{b}_{2}>1\right)$.

Todos os genótipos avaliados, à exceção do híbrido A 2003, mostraram os desvios da regressão estatisticamente diferente de zero, o que evidencia comportamento imprevisível nos ambientes considerados. Apesar disso, Cruz et al. (1989) consideram que aqueles materiais que apresentaram valores de $\mathrm{R}^{2}>80 \%$ não devem ter os seus graus de previsibilidade comprometidos. Assim, as cultivares que mostraram valores de $\mathrm{R}^{2}>80 \%$ apresentaram um bom ajustamento às retas de regressão.

Relacionando-se a estabilidade dos genótipos, avaliados no presente trabalho, com suas respectivas bases genéticas, infere-se que, à exceção do híbrido A 2003, todos os genótipos apresentaram a mesma resposta à estabilidade $\left(\sigma_{\mathrm{d} 1}^{2} \neq 0\right)$, independentemente de suas bases genéticas (híbrido simples, híbrido triplo, híbrido duplo e variedade) (Tabela 5). Resultados de trabalhos com cultivares de milho permitem inferir não haver uma relação fixa entre a homogeneidade ou heterogeneidade, de determinadas cultivares, e sua estabilidade; é possível selecionar cultivares mais estáveis que qualquer grupo, híbrido simples, híbrido triplo, híbrido duplo ou variedade (Gomes, 1990; Muniz, 1995; Carvalho et al., 2000; Ribeiro et al., 2000), o que foi também constatado no presente trabalho.

A cultivar ideal preconizada pelo modelo bissegmentado ( $\mathrm{b}_{0}>$ média geral, $\mathrm{b}_{1}<1, \mathrm{~b}_{1}+\mathrm{b}_{2}>1$ e desvio da regressão igual a zero) não foi encontrada no conjunto avaliado. Considerando-se o grupo de cultivares 
que expressou melhor adaptação ( $\mathrm{b}_{0}>$ média geral), não foi encontrada qualquer cultivar que atendesse a todos os requisitos necessários para adaptação nos ambientes desfavoráveis ( $b_{0}>$ média geral, $b_{1}<1$ e $\left.b_{1}+b_{2}<1\right)$. Apesar disso, os híbridos SHS 4040 e Agromen 3100, por apresentarem médias altas ( $\mathrm{b}_{0}>$ média geral), serem pouco exigentes nas condições desfavoráveis (estimativas de $b_{1}>1$ ), e mostrarem estimativas de $b_{1}+b_{2}$ semelhantes à unidade, podem ser recomendados para essa condição de ambiente. O híbrido A 2288, de média alta
( $b_{0}>$ média geral), estimativa de $b_{1}<1$, pode também ser recomendado para essa condição, apesar de mostrarse responsivo à melhoria ambiental.

Apesar dos híbridos Pioneer 3021 e Agromen 3050 serem exigentes nas condições desfavoráveis $\left(b_{1}<1\right)$, apresentaram bom desempenho produtivo nessas condições, o que sugere a possibilidade de também serem utilizados nesses ambientes. Os híbridos DAS 657, DAS 766 e SHS 5070, de adaptabilidade geral $\left(b_{1}=1\right)$ e alto desempenho nos ambientes desfavoráveis, podem também ser utilizados nessas condições desfavoráveis.

Tabela 5. Estimativas dos parâmetros de adaptabilidade e estabilidade de 46 cultivares de milho, em 22 ambientes do Nordeste brasileiro, segundo método de Cruz et al. (1989), no biênio 2000/2001-2001/2002.

\begin{tabular}{|c|c|c|c|c|c|c|c|c|}
\hline \multirow[t]{2}{*}{ Cultivares } & \multicolumn{3}{|c|}{ Médias nos ambientes } & \multirow[t]{2}{*}{$\mathrm{b}_{1}$} & \multirow[t]{2}{*}{$\mathrm{b}_{2}$} & \multirow[t]{2}{*}{$\mathrm{b}_{1}+\mathrm{b}_{2}$} & \multirow[t]{2}{*}{ QM desvio } & \multirow[t]{2}{*}{$\mathrm{R}^{2}$} \\
\hline & Geral & Desfavorável & Favorável & & & & & \\
\hline Agromen $3050^{(1)}$ & 6.668 & 4.878 & 7.907 & $1,11 *$ & $-0,32^{\mathrm{ns}}$ & $1,08^{\mathrm{ns}}$ & $1.954 .358 * *$ & 82 \\
\hline DAS $657^{(1)}$ & 6.619 & 4.976 & 7.757 & $1,04^{\mathrm{ns}}$ & $0,10^{\mathrm{ns}}$ & $1,14^{\mathrm{ns}}$ & $1.709 .392 * *$ & 83 \\
\hline DAS $766^{(1)}$ & 6.499 & 4.890 & 7.612 & $0,95^{\mathrm{ns}}$ & $0,71 * *$ & $1,66^{* *}$ & $1.333 .476 * *$ & 87 \\
\hline Pioneer $30 \mathrm{~F} 88^{(1)}$ & 6.351 & 4.531 & 7.611 & $1,12 *$ & $-0,37^{*}$ & $0,75^{\mathrm{ns}}$ & $1.679 .316^{* *}$ & 84 \\
\hline DAS $8550^{(1)}$ & 6.281 & 4.713 & 7.366 & $0,97^{\mathrm{ns}}$ & $0,85^{* *}$ & $1,83 * *$ & $2.135 .861 * *$ & 82 \\
\hline DAS $9560^{(1)}$ & 6.241 & 4.572 & 7.397 & $0,99^{\mathrm{ns}}$ & $0,13^{\text {ns }}$ & $1,00^{\mathrm{ns}}$ & $1.371 .774 * *$ & 84 \\
\hline A $2560^{(1)}$ & 6.155 & 4.239 & 7.481 & $1,21 * *$ & $-0,33 * *$ & $0,87^{\mathrm{ns}}$ & $2.852 .111^{* *}$ & 78 \\
\hline Pioneer $30 \mathrm{~F} 80^{(1)}$ & 6.085 & 4.421 & 7.237 & $1,04^{\mathrm{ns}}$ & $0,21^{\mathrm{ns}}$ & $1,26^{\mathrm{ns}}$ & $779.743 * *$ & 92 \\
\hline A $2288^{(1)}$ & 5.797 & 4.655 & 6.588 & $0,72 * *$ & $0,54 * *$ & $1,27 * *$ & $2.189 .788 * *$ & 70 \\
\hline A $2005^{1}$ & 5.421 & 3.888 & 6.483 & $0,93^{\mathrm{ns}}$ & $0,50 * *$ & $1,43 * *$ & $1.058 .798 * *$ & 88 \\
\hline SHS $5050^{(2)}$ & 6.543 & 4.690 & 7.825 & $1,14^{* *}$ & $-0,30^{*}$ & $0,84^{\mathrm{ns}}$ & $1.918 .545^{* *}$ & 83 \\
\hline SHS $5070^{(2)}$ & 6.496 & 4.950 & 7.567 & $0,98^{\text {ns }}$ & $-0,12^{\mathrm{ns}}$ & $0,85^{\mathrm{ns}}$ & $2.026 .969 * *$ & 78 \\
\hline Colorado $32^{(2)}$ & 6.184 & 4.227 & 7.538 & $1,18^{* *}$ & $-0,42 * *$ & $0,75^{\mathrm{ns}}$ & $1.340 .132 * *$ & 88 \\
\hline BRS $3060^{(2)}$ & 5.991 & 4.263 & 7.187 & $1,09^{\mathrm{ns}}$ & $-0,74 * *$ & $0,35 * *$ & $3.141 .944 * *$ & 72 \\
\hline Agromen $3150^{(2)}$ & 5.974 & 4.287 & 7.143 & $1,06^{\mathrm{ns}}$ & $0,23^{\mathrm{ns}}$ & $1,30^{*}$ & $1.982 .752 * *$ & 82 \\
\hline BR $3123^{(2)}$ & 5.879 & 4.014 & 7.170 & $1,14^{*}$ & $-0,59 * *$ & $0,54 * *$ & $1.749 .920 * *$ & 84 \\
\hline Agromen $3060^{(2)}$ & 5.830 & 4.175 & 6.977 & $1,03^{\mathrm{ns}}$ & $0,19^{\text {ns }}$ & $1,23^{\mathrm{ns}}$ & $2.031 .707 * *$ & 81 \\
\hline BRS $3101^{(2)}$ & 5.782 & 3.931 & 7.064 & $1,17 * *$ & $0,01^{\mathrm{ns}}$ & $1,17^{\mathrm{ns}}$ & $1.525 .861 * *$ & 87 \\
\hline A $3663^{(2)}$ & 5.658 & 4.156 & 6.698 & $0,96^{\mathrm{ns}}$ & $-0,07^{\mathrm{ns}}$ & $0,88^{\mathrm{ns}}$ & $2.334 .595^{* *}$ & 75 \\
\hline A $2003^{2}$ & 5.571 & 4.348 & 6.418 & $0,77 * *$ & $0,47 * *$ & $1,24^{\mathrm{ns}}$ & $583.983^{\mathrm{ns}}$ & 90 \\
\hline Pioneer $3021^{(3)}$ & 6.829 & 4.856 & 8.195 & $1,22 *$ & $-0,38 * *$ & $0,84^{\mathrm{ns}}$ & $1.278 .869 * *$ & 89 \\
\hline SHS $4040^{(3)}$ & 6.060 & 4.928 & 6.845 & $0,72 * *$ & $0,30 *$ & $1,02^{\mathrm{ns}}$ & $1.317 .089 * *$ & 77 \\
\hline Agromen $3100^{(3)}$ & 6.130 & 4.695 & 7.123 & $0,82 * *$ & $0,24^{\mathrm{ns}}$ & $1,07^{\mathrm{ns}}$ & $2.843 .305 * *$ & 67 \\
\hline BR $206^{(3)}$ & 5.904 & 4.269 & 7.036 & $1,01^{\mathrm{ns}}$ & $-0,18^{\text {ns }}$ & $0,82^{\text {ns }}$ & $1.090 .636 * *$ & 87 \\
\hline BRS $2110^{(3)}$ & 5.682 & 3.971 & 6.868 & $1,10^{\mathrm{ns}}$ & $-0,63 * *$ & $0,47 * *$ & $1.159 .707 * *$ & 88 \\
\hline AL Bandeirante $^{(4)}$ & 5.864 & 3.932 & 7.201 & $1,18^{* *}$ & $-0,25^{\mathrm{ns}}$ & $0,92^{\mathrm{ns}}$ & $1.648 .372 * *$ & 86 \\
\hline Sertanejo ${ }^{(4)}$ & 5.858 & 4.232 & 6.984 & $1,08^{\mathrm{ns}}$ & $0,16^{\mathrm{ns}}$ & $1,24^{\mathrm{ns}}$ & $1.646 .845^{* *}$ & 85 \\
\hline SHS 600 EX-200 $0^{(4)}$ & 5.853 & 4.127 & 7.047 & $1,10^{\mathrm{ns}}$ & $-0,25^{\mathrm{ns}}$ & $0,85^{\mathrm{ns}}$ & $1.224 .153 * *$ & 88 \\
\hline AL $34^{(4)}$ & 5.723 & 3.989 & 6.925 & $1,09^{\mathrm{ns}}$ & $-0,06^{\mathrm{ns}}$ & $1,02^{\text {ns }}$ & $1.092 .680 * *$ & 89 \\
\hline AL $30^{(4)}$ & 5.604 & 3.773 & 6.872 & $1,12 *$ & $0,06^{\mathrm{ns}}$ & $1,18^{\mathrm{ns}}$ & $1.222 .501 * *$ & 89 \\
\hline $\operatorname{CMS} 59^{(4)}$ & 5.355 & 3.592 & 6.576 & $1,10^{\mathrm{ns}}$ & $-0,17^{\mathrm{ns}}$ & $0,92^{\text {ns }}$ & $1.443 .011 * *$ & 86 \\
\hline São Francisco ${ }^{(4)}$ & 5.344 & 4.093 & 6.210 & $0,84 * *$ & $0,27^{\mathrm{ns}}$ & $1,12^{\mathrm{ns}}$ & $1.643 .499 * *$ & 92 \\
\hline Bozm Amarillo $^{(4)}$ & 5.285 & 3.600 & 6.452 & $1,04^{\mathrm{ns}}$ & $-0,24^{\mathrm{ns}}$ & $0,79^{\mathrm{ns}}$ & $972.203 * *$ & 89 \\
\hline Sintético Dentado ${ }^{(4)}$ & 5.251 & 3.547 & 6.431 & $1,04^{\mathrm{ns}}$ & $-0,10^{\mathrm{ns}}$ & $0,94^{\mathrm{ns}}$ & $709.983 *$ & 92 \\
\hline Asa Branca ${ }^{(4)}$ & 5.235 & 3.708 & 6.292 & $0,99^{\text {ns }}$ & $0,22^{\text {ns }}$ & $1,22^{\mathrm{ns}}$ & $2.153 .440 * *$ & 79 \\
\hline São Vicente ${ }^{(4)}$ & 5.221 & 3.603 & 6.342 & $1,01^{\mathrm{ns}}$ & $0,17^{\mathrm{ns}}$ & $1,18^{\mathrm{ns}}$ & $2.480 .631 * *$ & 77 \\
\hline AL Manduri ${ }^{(4)}$ & 5.144 & 3.635 & 6.189 & $0,96^{\mathrm{ns}}$ & $-0,02^{\mathrm{ns}}$ & $0,93^{\mathrm{ns}}$ & $1.056 .648 * *$ & 87 \\
\hline BRS $4150^{(4)}$ & 5.121 & 3.584 & 6.186 & $0,95^{\mathrm{ns}}$ & $0,12^{\mathrm{ns}}$ & $1,08^{\mathrm{ns}}$ & $936.923 * *$ & 88 \\
\hline Sintético Duro ${ }^{(4)}$ & 4.989 & 3.482 & 6.034 & $0,90^{\mathrm{ns}}$ & $-0,01^{\mathrm{ns}}$ & $0,88^{\text {ns }}$ & $745.953 * *$ & 89 \\
\hline Cruzeta $^{(4)}$ & 4.978 & 3.534 & 5.978 & $0,89 *$ & $0,15^{\mathrm{ns}}$ & $1,04^{\mathrm{ns}}$ & $1.140 .591 * *$ & 85 \\
\hline BR $106^{(4)}$ & 4.960 & 3.120 & 6.234 & $1,12 * *$ & $-0,27^{\mathrm{ns}}$ & $0,84^{\mathrm{ns}}$ & $1.148 .879 * *$ & 89 \\
\hline Saracura $^{(4)}$ & 4.910 & 3.512 & 5.879 & $0,89^{*}$ & $-0,23^{\mathrm{ns}}$ & $0,66^{*}$ & $1.423 .458 * *$ & 80 \\
\hline Assum Preto $^{(4)}$ & 4.906 & 3.525 & 5.862 & $0,88^{*}$ & $0,14^{\mathrm{ns}}$ & $1,02^{\mathrm{ns}}$ & $1.314 .045^{* *}$ & 83 \\
\hline BR $473^{(4)}$ & 4.845 & 3.437 & 5.820 & $0,86 * *$ & $0,01^{\mathrm{ns}}$ & $0,88^{\text {ns }}$ & $1.240 .700 * *$ & 82 \\
\hline CMS $35^{(4)}$ & 4.573 & 3.393 & 5.390 & $0,77 * *$ & $0,06^{\mathrm{ns}}$ & $0,82^{\text {ns }}$ & $1.859 .700^{* *}$ & 71 \\
\hline CMS $47^{(4)}$ & 3.937 & 3.015 & 4.560 & $0,55^{* *}$ & $0,01^{\mathrm{ns}}$ & $0,56^{* *}$ & $1.108 .199 * *$ & 68 \\
\hline
\end{tabular}

${ }^{(1)}$ Híbrido simples. ${ }^{(2)}$ Híbrido triplo. ${ }^{(3)}$ Híbrido duplo. ${ }^{(4)}$ Variedade. ns Não-siginificativo. * e **Significativamente diferentes da unidade, para b ${ }_{1}$ e $\mathrm{b}_{1}+\mathrm{b}_{2}$, e de zero, para $\mathrm{b}_{2}$, pelo teste $\mathrm{t}$ de Student, a $5 \%$ e a $1 \%$ de probabilidade, respectivamente. 
No grupo de cultivares de melhor adaptação, também não foi encontrada qualquer cultivar que atendesse a todos os requisitos necessários para adaptação nos ambientes favoráveis ( $b_{0}>$ média geral, $b_{1}$ e $b_{1}+b_{2}>1$ ). Mesmo assim, os híbridos Pioneer 3021, Agromen 3050, SHS 5050, Pioneer 30 F 88, Colorado 32, BR 3123, BRS 3101 e a variedade AL Bandeirante atenderam a um número maior de requisitos para recomendação nessas condições (estimativas de $b_{0}>$ média geral e $b_{1}>1$ ). Os híbridos DAS 766, DAS 8550 e Agromen 3150, que apresentaram estimativas de $b_{0}>$ média geral, e responderam à melhoria ambiental $b_{1}+b_{2}>1$, podem, também, ser recomendados para os ambientes favoráveis. Os híbridos com estimativas de $b_{0}>$ média geral e $b_{1}=1$, evidenciaram adaptabilidade geral, justificando sua recomendação para a Região Nordeste do Brasil, destacando-se entre elas os DAS 657, DAS 766, SHS 5070, DAS 8550.

Considerando-se a média geral das variedades (5.188 $\mathrm{kg} \mathrm{ha}^{-1}$ ), infere-se que as que mostraram produtividade média superior a esse valor evidenciaram boa adaptação às condições edafoclimáticas da região. Nesse grupo, as variedades AL Bandeirante e AL 30 mostraram-se exigentes nas condições desfavoráveis $\left(b_{1}>1\right)$, e o Sintético Dentado mostrou-se pouco exigente. As variedades Sertanejo e Asa Branca, bastante difundidas na região, juntamente com AL 34, CMS 59, Bozm Amarillo, Sintético Duro e São Vicente, repetiram o bom comportamento (Cardoso et al., 2000; Carvalho et al., 2001, 2002). As variedades Cruzeta e Assum Preto, apesar de demonstrarem baixa adaptação, sua superprecocidade contitui forte justificativa para seu uso nas áreas do semi-árido, por reduzirem o risco de frustração de safras nessa região. A variedade Assum Preto, por ser também um material de alta qualidade protéica, pode ser utilizada em programas de combate à fome e à miséria.

\section{Conclusões}

1. As magnitudes das variâncias das interações cultivares $\mathrm{x}$ locais e cultivares $\mathrm{x}$ anos revelam que é mais vantajoso avaliar as cultivares em um maior número de locais.

2. A cultivar ideal, preconizada pelo modelo bissegmentado, não faz parte do conjunto avaliado.

3. Os híbridos apresentam melhor adaptação do que as variedades, destacando-se nos ambientes favoráveis:
Pioneer 3021, Agromen 3050, SHS 5050, Pioneer 30 F 88, Colorado 32, BRS 3123.

4. As variedades e os híbridos de melhor adaptação ( $b_{0}>$ média geral), e com estimativas de $b_{1}$ semelhantes à unidade, têm importância expressiva nos diferentes sistemas de produção do Nordeste brasileiro.

\section{Referências}

ARIAS, E.R.A. Adaptabilidade e estabilidade de cultivares de milho no Estado do Mato Grosso do Sul e avanço genético obtido no período de 1986/87 a 1993/94. 1996. 118p. Tese (Doutorado) Escola Superior de Agricultura de Lavras, Lavras.

ATROCH, A.L.; SOARES, A.A.; RAMALHO, M.A.P. Adaptabilidade e estabilidade de linhagens de arroz de sequeiro testados no Estado de Minas Gerais. Ciência e Agrotecnologia, v.24, p.541-548, 2000.

CARBONELL, S.A.M.; AZEVEDO FILHO, J.A. de; DIAS, L.A. dos S.; GONÇALVES, C.; ANTÔNIO, C.B. Adaptabilidade e estabilidade de produção de cultivares e linhagens de feijoeiro no Estado de São Paulo. Bragantia, v.60, p.69-77, 2001.

CARDOSO, M.J.; CARVALHO, H.W.L. de; LEAL, M. de L. da S.; SANTOS, M.X. dos. Comportamento, adaptabilidade e estabilidade de híbridos de milho no Estado do Piauí no ano agrícola de 1998. Revista Científica Rural, v.5, p.146-153, 2000.

CARNEIRO, P.C.S. Novas metodologias de análise de adaptabilidade e estabilidade de comportamento. 1998. 168p. Tese (Doutorado) - Escola Superior de Agricultura de Lavras, Lavras.

CARVALHO, H.W.L. de; LEAL, M. de L. da S.; CARDOSO, M.J.; SANTOS, M.S. dos; TABOSA, J.N.; CARVALHO, B.C.L. de; ALBUQUERQUE, M.M.; SANTOS, D.M. Adaptabilidade e estabilidade de cultivares de milho no Nordeste brasileiro no ano agrícola de 1998/99. Agrotrópica, v.12, p.21-28, 2000.

CARVALHO, H.W.L. de; LEAL, M. de L. da S.; CARDOSO, M.J.; SANTOS, M.S. dos; CARVALHO, B.C.L. de; TABOSA, J.N.; LIRA, M.A.; ALBUQUERQUE, M.M. Adaptabilidade e estabilidade de cultivares de milho no Nordeste brasileiro no ano agrícola de 1998. Pesquisa Agropecuária Brasileira, v.36, p.637-644, 2001.

CARVALHO, H.W.L. de.; LEAL, M. de L da S.; CARDOSO, M.J.; SANTOS, M.X. dos; TABOSA, J.N.; SANTOS, M.D. dos; LIRA, M.A. Adaptabilidade e estabilidade de híbridos de milho em diferentes condições ambientais do Nordeste brasileiro. Revista Brasileira de Milho e Sorgo, v.1, p.75-82, 2002.

CRUZ, C.D.; TORRES, R.A. de; VENCOVSKY, R. An alternative approach to the stability analysis by Silva and Barreto. Revista Brasileira de Genética, v.12, p.567-580, 1989.

GAMA, E.E.G.; PARENTONI, S.N.; PACHECO, C.A.P.; OLIVEIRA, A.C. de; GUIMARÃES, P.E. de O. de; SANTOS, M.X. dos. Estabilidade de produção de germoplasma de milho avaliado em diferentes regiões do Brasil. Pesquisa Agropecuária Brasileira, v.36, p.1143-1149, 2000.

GOMES, M. de S. Interação genótipos x épocas de plantio em milho (Zea mays L.) em dois locais do oeste do Paraná. 1990. 
148p. Dissertação (Mestrado) - Escola Superior de Agricultura Luiz de Queiroz, Piracicaba.

MUNIZ, J.A. Avaliação da estabilidade de cultivares de milho em diferentes níveis de adubação e locais da região de Lavras, MG. 1995. 60p. Dissertação (Mestrado) - Escola Superior de Agricultura de Lavras, Lavras.

PIMENTEL-GOMES, F. Curso de estatística experimental. 11.ed. rev. e ampl. São Paulo: Nobel, 1985. 466p.

RAMALHO, M.A.P.; SANTOS, J.B. dos; ZIMMERMANN, M.J. de $O$. Genética quantitativa em plantas autógamas: aplicação no melhoramento do feijoeiro. Goiânia: UFG, 1993. cap.6, p.131-169. (Publicação, 120).

RIBEIRO, P.H.E.; RAMALHO, M.A.P.; FERREIRA, D.F. Adaptabilidade e estabilidade de cultivares de milho avaliadas em diferentes condições ambientais do Estado de Minas Gerais. In: REUNIÓN LATINOAMERICANA DEL MAIZ, 280., 2000, Sete
Lagoas, MG. Memórias. Sete Lagoas: Embrapa Milho e Sorgo; CIMMYT, 2000. p.251-260.

SAS INSTITUTE (Cary, Estados Unidos). SAS/STAT user's guide: version 6. $4^{\text {th }}$ ed. Cary, 1996. v.1.

SCAPIM, C.A.; CARVALHO, C.G.P. de; CRUZ, C.D. Uma proposta de classificação dos coeficientes de variação para a cultura do milho. Pesquisa Agropecuária Brasileira, v.30, p.683-686, 1995.

SILVA, F.B.R. de; RICHE, G.R.; TORNGAU, J.P.; SOUSA NETO, N.C. de; BRITO, L.T. de L.; CORREIA, R.C.; CAVALCANTI, A.C.; SILVA, F.H.B.B. da; SILVA, A.D. da; ARAÚJO FILHO, J.C. de; LEITE, A.P. Zoneamento ecológico do Nordeste: diagnóstico do quadro natural e agrossocioeconômico. Rio de Janeiro: EmbrapaCNPS; Embrapa-Cpatsa, 1993. v.1.

VENCOVSKY, R.; BARRIGA, P. Genética biométrica no fitomelhoramento. São Paulo: Sociedade Brasileira de Genética, 1992. 496p.

Recebido em 6 de outubro de 2003 e aprovado em 15 de dezembro de 2004 